\title{
Navegação de cabotagem - um economista revê-se ao longo (do primeiro semestre) da pandemia
}

https://doi.org/10.21814/uminho.ed.25.1

\section{Paulo Reis Mourão}

Paulo Reis Mourão (ORCID: 0000-0001-6046-645X) é Professor Associado com agregação do Departamento de Economia da Escola de Economia e Gestão da Universidade do Minho (EEG) e investigador do NIPE. É autor de várias dezenas de artigos científicos indexados e de vários livros focados na Economia, nas Finanças Públicas, na Economia Social e na Economia do Desporto. Presença assídua nos meios de comunicação social nacionais e internacionais, conta com vários prémios de reconhecimento científico. 


\section{INTRODUÇÃO}

A pandemia identificada como COVID-19 atingiu a economia portuguesa em 2020. Os impactos fizeram-se sentir, quer nos mecanismos associados à procura global (quer interna, quer externa), quer nos efeitos derivados da imposição pública de um conjunto de fases identificado com o denominado "Período de Confinamento".

Este contributo pessoal responde ao convite formulado pela Senhora Vice-Reitora, a Professora Doutora Manuela Martins. Ainda que, envolvendo o convite, tivesse perpassado a garantia da liberdade atribuída de definição dos conteúdos, procurei cingir o presente texto a uma leitura crítica possível a partir da distância entre o momento da redação deste texto (nos inícios de agosto de 2020) ao conjunto de respostas que dei ao jornalista António Gonçalves Rodrigues (Lusa/Mensageiro de Bragança), em três momentos em que fui entrevistado sobre a evolução percebida no alcance demográfico e económico da pandemia. Como é óbvio, agradeço a autorização do António Gonçalves Rodrigues (por sinal, 'alumni' da Universidade do Minho) para a transcrição dos conteúdos destas entrevistas.

Como se verá, a realidade visada pelas entrevistas era a economia de um espaço específico do território nacional - a área do Interior Norte. No entanto, as respostas facilmente poderão ser estendidas à generalidade do território de menor densidade populacional em Portugal, nomeadamente, o Alto Minho, os concelhos a montante do Cávado e do Ave e à maioria das áreas a leste da Nacional 2. Portanto, este contributo possibilita uma visão complementar das vivências em torno da COVID-19 em Portugal, para lá das expressóes mais comuns que objetivam as áreas mais densas.

Finalmente, existe um foco transversal às três entrevistas transcritas - o Indicador de Trás-os-Montes e Alto Douro, tratado por IETI. Trata-se de um indicador de difusão cuja construção e divulgação é da minha responsabilidade. A primeira edição mensal do IETI aconteceu em outubro de 2017. Desde então, entre os dias 20 e 27 de cada mês, distribuo um pequeno inquérito de três perguntas a um conjunto amostral de residentes na região de Trás-os-Montes e Alto Douro, inquirindo-os sobre a perceção pessoal relativamente à evolução nos gastos familiares, nas obras públicas na vizinhança e no fluxo de turistas chegados à região. Com uma margem de erro média em redor dos 
$15 \%$, tem permitido esboçar uma série de valores que, no fundo, representam a leitura que os residentes no Interior Norte fazem da economia em redor. O Mensageiro de Bragança, através da Direção (liderada por António Gonçalves Rodrigues), tem sido o órgão da Comunicação Social que mais atenção tem prestado a este Indicador, que mostrou oscilaçóes significativas no período da COVID-19, como se salientará no conteúdo deste trabalho.

Assim, este documento salienta as três entrevistas realizadas neste período visando a evolução do IETI e a respetiva sincronia com o ciclo nacional desde março de 2020. Cada entrevista, além da transcrição integral, inclui uma reflexão crítica.

Assim, longe de elaborar um texto no formato tradicional de um artigo científico, acredito que o formato que aqui proponho se coaduna melhor com os objetivos expostos no convite em prol da edição de um volume de coautoria de um número significativo de investigadores e professores da Universidade do Minho, combinando a reflexão pessoal com a revisão crítica da multidão de experiências individuais e coletivas que os vários ritmos de pandemia proporcionaram. Rever o que ensinámos/ensinamos, aquilo que escrevemos, aquilo que investigámos/investigamos é um passo essencial na nossa essência-vocação de ser Académico; portanto, o exercício de revisão que se segue ajuda-nos a perceber aonde chegámos, o que percorremos e o que mudámos ou temos de mudar. Passos essenciais quando o desafio surge sob a forma de algo invisível aos olhos, impercetível aos sentidos, sob a forma de um vírus batizado no espaço mediático como SARS-CoV-2 e que usa a humanidade e a proximidade humana - aquela capacidade que nos fez evoluir, sobreviver e inclusive, transcender - para nos fragilizar, nos diminuir e nos separar.

O presente trabalho termina com alguns parágrafos esboçando uma síntese conclusiva dos conteúdos, mas também perspetivas de leituras e de desafios nos tempos mais imediatos.

\section{PRIMEIRA ENTREVISTA (16 de março de 2020)}

A primeira entrevista aconteceu, através de uma troca de correio eletrónico, nos dias 15 e 16 de março de 2020. A Universidade do Minho tinha suspendido as atividades 
letivas presenciais na semana anterior devido à confirmação de um caso positivo envolvendo um discente. Nessa semana, outras instituiçóes do Ensino Superior tinham também suspendido as atividades por motivos próximos e adivinhava-se, com a experiência observada noutros países que tinham tido casos positivos identificados antes do primeiro em solo português, que período(s) de confinamento seriam decretados pelo Governo, generalizando a suspensão das aulas de todos os níveis de ensino pré-universitário que tinha começado a ocorrer na segunda-feira dia 16 de março. O conteúdo desta entrevista, entre António Gonçalves Rodrigues (AGR) e Paulo Reis Mourão (PRM) foi o seguinte.

AGR: Previsóes para o impacto da COVID na economia transmontana?

PRM: As várias análises a partir do IETI [Índice da Economia de Trás-os-Montes e Alto Douro, da responsabilidade de PRM] mostram que a economia transmontana tem ciclos próximos dos da economia nacional. Em média, episódios pandémicos têm tido valores de referência na ordem dos 1-2\% de quebra no produto per capita nos países afetados. Há também uma certa sobre-reação no período posterior, com crescimento significativo dos gastos públicos e privados. A nossa economia transmontana, com a sua especificidade, dependente do setor público nacional e com dificuldades de alavancagem do investimento próprio, vai sofrer com as restriçôes nos hábitos de consumo, com a fragilidade de algumas unidades produtivas da região e com a quebra notória no turismo (a variável que para mim mais vai demorar a reagir). A favor temos a transmontanidade - o comércio local pode aproveitar o momento para ver algumas lojas desaparecerem, mas aqueles negócios que tiveram alguns recursos acumulados e sobretudo de gestão familiar não sentirão de sobremaneira a quebra no consumo como as grandes cadeias com centenas de funcionários e valores empatados nos fornecimentos e nas entregas. Dependendo da duração, diria que podemos esperar uma quebra na faturação esperada no comércio em redor de 5-7\% do ano passado por cada mês de quarentena.

AGR: Conseguiremos recuperar ou haverá danos irreparáveis? De que tipo?

PRM: Acho que fui respondendo na primeira questão. Houve sempre recuperação, mas também houve danos irreparáveis na economia e sobretudo na demografia. Um estudo 
interessante sobre a pneumónica em Trás-os-Montes de há 100 anos é o do António Conde (2018. "A Pneumónica ou gripe espanhola em Vila Real (1918-1919) - um olhar”. Tellus/ Revista de cultura transmontana e duriense. Grémio Literário de Vila Real).

AGR: O superavit previsto para este ano fica comprometido?

PRM: Isso é mais que certo (já antes o era quase em surdina...)

AGR: Que medidas deveriam ser tomadas para mitigar os efeitos junto das empresas?

PRM: Tantas medidas que ainda não foram avançadas. Desde logo, um plano de higienização laboral urgente de modo a que a produção não fique ainda mais comprometida, motivando os trabalhadores para o trabalho em segurança. A suspensão das obrigações fiscais pelo menos em dois meses. $\mathrm{O}$ reforço da linha de apoio a dificuldades de tesouraria e a associação do Estado a esquemas de seguros de produção, distribuição e armazenamento, bem como a reconversão das empresas com dificuldades de tesouraria e operacionalidade.

AGR: Em termos de propagação, o que dizem os modelos? O que poderemos esperar? Quais as áreas económicas mais afetadas?

PRM: Também fui respondendo nas anteriores. Até agora, percebemos todos alguns pontos. O contágio é elevado. A morbilidade é alta em termos de grupos de risco. Portanto, a profilaxia existente - enquanto não surgir medicamento alternativo - tem sido a de uma certa 'solidariedade com os grupos de risco'. Nenhum de nós sabe como o organismo reagiria com a COVID-19 e, portanto, na dúvida podemos aceitar que temos uma probabilidade razoável de pertencer ao grupo de risco. Mas a maioria dos casos tem sido tratado assintomaticamente ou com sintomas comuns aos de uma gripe. Parece-me que vamos ter aquilo que na "Economia do Comportamento" se apelida de 'exaustão da paciência' ou 'relativização do risco', isto é, o risco moral - quando os Sistemas de Saúde (Públicos + Privados) perceberem uma certa capacidade de acomodar os casos mais graves (não todos os atuais infetados) - capacidade que agora não está segura - vão diminuir as defesas impostas à população, até porque a própria população aguenta quarentenas/estados de sítio com alguma limitação temporal e psicológica. 
AGR: Qual o tempo de paragem a partir do qual a economia começa a sofrer danos irreparáveis?

PRM: A generalidade dos setores produtivos - até pela perecibilidade das matérias de base - começa a sofrer de histerese a partir de 3 meses. Mas outros setores (e cada agente/ empresa) tem prazos diferentes, geralmente mais curtos.

AGR: Já houve outra situação semelhante a esta?

PRM: Nunca há duas crises epidémicas/pandémicas iguais. Em solo europeu, a mais recente e com magnitude brutal foi a gripe espanhola: de há 100 anos, comentada pelos nossos avós. Talvez a mensagem global seja a de que i) nada vai ficar como dantes no nosso mundo; ii) os sobreviventes vão receber tempos recheados de oportunidades e desafios (e de crescimento económico) e iii) a nossa Região Transmontana pelas suas características pode não ter a severidade dos espaços mais urbanizados e pode receber a fase pós-COVID-19 como uma janela de oportunidades que agora não se vislumbram (até porque geralmente quem melhor sai destas crises é quem - além de sobrevivente natural - soube acumular 'capitais' que outros perderam, capitais financeiros, mas também capital social, capital cultural e negocial.

\section{REVISÃO CRÍTICA DAS RESPOSTAS DADAS}

Na questão das previsóes, a quebra do PIB dada como resposta visava a quebra esperada por cada mês atingido. Desde o início do ano de 2020, com o avolumar dos números da pandemia em solo chinês e rapidamente a partir do primeiro foco europeu (o Norte da Itália), diversas projeçóes começaram a ser partilhadas a partir de trabalhos da imprensa norte-americana. Um desses trabalhos (Carlsson-Szlezak, P., Reeves, M, Swartz, P. (2020). "What Coronavirus Could Mean for the Global Economy”. Harvard Business Review. March 3, 2020) possibilitava essa projeção. Atualmente, seis meses depois do início da pandemia em solo português, as projeçóes revelam uma quebra esperada no PIB português de 2020, que oscila entre os $8 \%$ (estimados pelo FMI em abril de 2020) e os 13\% (estimados pelo Banco de Portugal, em junho de 2020). Relativamente ao défice público, as estimaçôes também oscilaram entre os $7 \%$ do Ministério das Finanças (em abril de 2020) e os 9\% do Conselho das Finanças Públicas (em junho 
de 2020). Sobre o efeito de histerese sentido em vários setores de atividade económica, um indicador reflexivo é a taxa de desemprego, cujas projeçóes para Portugal oscilaram entre os 10\% (em 26 de março, pelo Banco de Portugal) e os 11\% (do cenário-base antecipado pelo Conselho das Finanças Públicas, em junho de 2020), sentido sobretudo nas áreas de turismo, viagens, restauração e hotelaria. De qualquer modo, no mínimo, um salto de 4 pontos percentuais, a partir dos 6\% oficializados para 2019, reflexivo, também, das várias fases de confinamento/distanciamento social, que tiveram o pico de imposição/adesão da população entre 19 de março (início da primeira fase do Estado de Emergência) e 1 de julho (final do Estado de Calamidade nacional).

Além das tendências de agravamento da queda da produção nacional assim como do saldo das contas públicas, a evidência acumulada nestes seis meses permitiu validar algumas das respostas sugeridas nesta primeira entrevista. Assim, foram particularmente validadas a sugestão da difícil 'paciência' dos portugueses face aos períodos (mais tardios) de confinamento decretados, bem como o turismo (local e nacional) enquanto setor económico particularmente afetado pela pandemia (agravado pelas restrições de mobilidade ou a obrigatoriedade de quarentenas à chegada impostas por vários países tradicionalmente clientes da oferta turística portuguesa).

No entanto, uma projeção minha não se observou como eu esperava - a menor letalidade provocada (no mínimo, de modo direto) pela pandemia na região do Interior Norte. Se, por um lado, é verdade que os números atualmente disponibilizados mostram que a gripe espanhola de há cem anos foi significativamente mais letal na generalidade das regióes portuguesas do que a COVID-19, por outra via, o Interior Norte teve uma taxa de morbilidade (Número de Mortes diretamente provocadas pela COVID-19 sobre Número de Casos Positivos de COVID-19) que rondou os $8 \%$, quando o respetivo indicador para o país está atualmente em 3.7\%. Ainda que tenha escasseado uma discussão focada nestes desequilíbrios territoriais, a forma como a pandemia era extremamente mortífera para os grupos de risco (sobretudo, cidadãos com idade superior a 70 anos) bem como a concentração demográfica no Interior Norte de uma população envelhecida, não pode ser deixada de fora dessa discussão, onde também poderá ser discutida a qualidade da assistência disponibilizada nas Unidade de Cuidados Continuados que acolheram os casos mais graves da região. Friso aqui a questão 
adicional, sublinhada no último mês, da mortalidade maior observada em junho-julho de 2020, face a períodos homólogos, questionando os efeitos 'indiretos' da pandemia quer na qualidade da oferta de suportes de saúde públicos e privados, quer no enviesamento induzido na população, que passou a procurar significativamente menos consultas e tratamentos médicos e clínicos presenciais.

\section{SEGUNDA ENTREVISTA (28 de abril de 2020)}

A segunda entrevista ocorreu entre os dias 27 e 28 de abril de 2020, também através de correio eletrónico. O país tinha passado o período de maior número diário de novos casos ocorrido no início do mês, bem como o período de Páscoa tinha sido também vivido de forma completamente diferente do habitual. Por exemplo, em minha casa, não houve a habitual reunião familiar alargada, bem como o almoço pascal foi encomendado e entregue na porta. As normas de distanciamento social continuavam a imperar nos finais de abril, ainda que a rigidez do confinamento mais severo (isto é, alargado à generalidade dos setores produtivos) já só atingisse algumas áreas económicas. No entanto, a generalidade dos gerentes de lojas fazia sentir a frustração pela inexistência de faturação suficiente bem como pela dificuldade da retoma dos ritmos de consumo. Nessa sequência, aproveitando a edição mensal que desenvolvo há dois anos do IETI (Índice de Economia de Trás-os-Montes e Alto Douro), para o Mensageiro de Bragança, António Gonçalves Rodrigues começava a segunda entrevista por auscultar a minha leitura da evolução desse Índice. Segue a transcrição desta segunda entrevista.

AGR: Sobre o IETI, temos dados do primeiro mês com a economia parada. O que nos dizem?

PRM: Dizem-nos que caímos 83\% em relação ao valor de um ano. Atingiu-se o mínimo histórico de registos do IETI em dois anos e meio. O valor de 20.2 pode ser interpretado do seguinte modo: os transmontanos que reconhecem que a economia está pior são 3 vezes aqueles que reconhecem que a economia está igual ou melhor. Portanto, as pessoas gastaram muito menos em abril do que em março, veem menos obras, e não vislumbram sequer turistas no horizonte. 
AGR: Diferem da média nacional?

PRM: Este índice tem o mérito único de desagregar a perceção a nível regional, algo que só Trás-os-Montes tem. No entanto, os vários inquéritos saídos na última semana e representativos do sentimento nacional mostram resultados convergentes. Quebra da confiança dos consumidores e investidores, receios múltiplos quanto ao futuro, incertezas socioeconómicas variadas.

AGR: A este ritmo, quanto pode perder a economia transmontana até ao verão?

PRM: Quando o Mensageiro de Bragança me entrevistou em março, propus uma quebra de $7 \%$ por cada mês de inatividade. Mantenho essa estimativa para a generalidade dos setores, com a agravante que as quebras tendem a ser progressivas: $7 \%$ no primeiro mês, $10 \%$ no segundo, $20 \%$ no terceiro, etc. No entanto, o desconfinamento é um recurso que parece um tango ou um jogo de xadrez - a economia e a sociedade darão alguns passos, a doença virá atrás, a economia e a sociedade responderão, a doença terá outra reação, etc. Temos tido uma região transmontana com aparentemente ritmos de contágios controlados - nos últimos 15 dias os concelhos mais infetados têm tido uma média de dois casos em cada três dias e os restantes, tirando os saltos por contágio institucional (lares ou comunidades), tem mais um caso em cada 5 ou 6 dias. Isto leva-me a defender um desconfinamento faseado, que deveria relançar primeiro a economia das regióes menos infetadas. Mas o Governo, numa lógica de equidade territorial, vai desconfinar a todos por igual. Também pouco a pouco as pessoas - sobretudo num contexto mais urbano - 'precisam' de ir saindo, de reganhar ritmos de vida social, o que poderá fazer com que maio seja um mês com alguma recuperação [face] ao marasmo de abril. De qualquer modo, a generalidade dos rendimentos em Trás-os-Montes está diretamente ou indiretamente ligado ao setor público, quer por via de salários, quer por via de transferências sociais; até ao momento o setor público não introduziu reduções nestas variáveis, o que possibilita a manutenção de algum poder de compra regional, até mesmo durante o verão. Agora, o setor do turismo quando muito terá alguma dinâmica - sempre longe do passado recente - em função dos turistas nacionais (e nas áreas de fronteira reabertas, de turistas espanhóis) - e sempre com muito condicionamento higiénico e vigilância das autoridades (o que por si só são fatores inibidores). 
AGR: Quais os setores mais afetados?

PRM: O IETI mostrou quebras em 75\% (em média) das perceções sobre gastos locais, obras e turismo.

\section{REVISÃO CRÍTICA DAS RESPOSTAS DADAS}

O Índice da Economia de Trás-os-Montes, projeto pessoal iniciado em outubro de 2017, nunca tinha conhecido o valor que conheceu em abril de 2020. Efetivamente, o mínimo alcançado (20.2) e tratando-se de um Índice de Difusão (isto é, de auscultação da perceção económica dos agentes representados pela amostra inquirida) revelava, numa leitura simples, que o número de pessoas que reconhecia que em abril a economia tinha piorado face a março era 3 vezes superior ao número de pessoas que tinha outra perceção sobre a evolução em análise. Nesse mesmo período (finais de abril), diversos outros índices (nacionais e comunitários) corroboravam que consumidores e investidores estavam pessimistas, quer sobre o que se tinha passado em termos económicos, quer sobre o que a economia poderia mostrar nos tempos futuros mais próximos.

Em termos de evolução da pandemia, os números nacionais atingidos em finais de abril pareciam esconder o choque negativo que se verificaria entre maio e junho em Lisboa e Vale do Tejo. A Região Norte (sobretudo, o Norte Litoral) tinha sido até então a região identificada pela Direção Geral de Saúde como a mais severamente atingida em números de contágios e de mortes. No entanto, desde meados de abril, a generalidade dos espaços do Norte vinha mostrando uma redução dos casos ativos o que combinava com a leitura positiva que alguma imprensa internacional vinha fazendo do exemplo português. Os ritmos de contágio na região Norte tinham sido sobretudo alimentados por fatores laborais, mas também - especialmente em concelhos do interior - por focos institucionais (nomeadamente, lares e unidades de internamento clínico). Tenho um trabalho em submissão, assinado também por Ricardo Bento (da Universidade de Trás-os-Montes e Alto Douro), sobre a autocorrelação espacial dos contágios, diferenciando casos por milhar de habitante, mas também casos por densidade populacional (que mostra claramente a presença de 'casos especiais' em determinados municípios de baixa densidade e onde o contágio se processou sobretudo pelos tais focos institucionais). 
Em abril, defendia aquilo que, em 'imagem de negativo', o Estado faria para Lisboa e Vale do Tejo a partir de maio - o desconfinamento diferenciado. Na altura, com base em ensaios que países da Europa Central estavam a realizar, mas também observando vários exemplos da História Económica e das pandemias, eu encontrava vantagens em libertar as regiốes mais bem-sucedidas no combate, nomeadamente, as regiôes de baixa densidade e os seus setores poderiam ter um estímulo positivo nessa diferenciação. Em contrapartida, a imagem 'todos pagam por alguns' que estava a ser seguida, parecia castigar por exemplo o Norte Interior (mais controlado) devido ao Norte Litoral. Obviamente compreendia as exigências administrativas, sanitárias e inclusive de ordem pública por detrás de pretensóes de eficiência desta medida de desconfinamento diferenciado. No entanto, os exemplos citados apresentavam resultados positivos compensadores. Curiosamente, em maio e junho, a generalidade do país avançou para desconfinamentos cada vez mais generosos e Lisboa e Vale do Tejo permaneceu debaixo de medidas de controlo, com algumas freguesias severamente vigiadas pelas autoridades devido ao número crítico de casos ativos residentes.

Neste período, escutando muitos gerentes de lojas e de restauração, amigos e conhecidos, assim como empresários de outros ramos e alguns industriais, percebia que a solução de curto prazo de dinamização do consumo ecoada por alguns economistas não bastava para motivar a população. Assinei vários artigos de opinião sobre o assunto e apoiava-me não só em episódios históricos, mas também nas assunções clássicas da Microeconomia e da Macroeconomia, nomeadamente, na capacidade limitada de usufruto que o consumo nos proporciona bem como nas restriçốes naturais de armazenamento (mesmo desconsiderando o poder da restrição de rendimentos). Aquilo que a economia portuguesa - e também a generalidade das economias europeias - vivia era um clima de 'poupança mórbida', na designação de John Hobson. O Setor Público não tinha induzido quebras nas remunerações dos seus colaboradores pelo que regióes dependentes não sentiam quebras reais nos rendimentos em abril de 2020; no entanto, os canais de consumo estavam estiolados. Daí, era importante canalizar os valores acumulados 'involuntariamente' para os setores necessitados de 'dinheiro vivo', nomeadamente o comércio, a restauração, etc. Recuperei como propostas as experiências bem-sucedidas de dinamização de investimento local dos Bancos Comunitários de 
Desenvolvimento (amplamente implementados no continente americano e no entanto com tanta falta evidente no europeu), assim como a necessidade de criação de instrumentos de financiamento local nos negócios necessitados de meios de pagamento, através de bolsas locais ou de entidades emissoras de obrigações do comércio local. Através destas entidades, pequenos investidores locais poderiam ajudar hoje os comerciantes em volta, evitando a subida tão significativa dos impostos em períodos futuros, devido às pressóes sobre o Estado Social pela subida esperada no desemprego. A esta distância, e mesmo agora que os ritmos de consumo se aproximam das médias de verão mas também se verifica o encerramento definitivo de muitos negócios, continuo - com outros colegas - a considerar estas propostas relevantes.

\section{TERCEIRA ENTREVISTA (31 de julho de 2020)}

A terceira entrevista aconteceu entre os dias 30 e 31 de julho de 2020. O país tinha deixado de ser o 'bom exemplo internacional', muito devido ao abalo na reputação deixado pela exclusão de Portugal das listas de países ‘sugeridos' pelo Reino Unido para turismo dos britânicos sem a necessidade de quarentenas obrigatórias no regresso. No entanto, a economia nacional ia mostrando alguma reação devido à procura interna e as altas temperaturas de julho tinham dinamizado ritmos de turismo menos afastados do que seria o ritmo esperado sem o contexto pandémico. O campeonato profissional de futebol sénior fora retomado em inícios de junho e a época desportiva da modalidade terminava, sem público nas bancadas, a 1 de agosto, com a Taça de Portugal. A partir da última semana de julho, com a situação pandémica a ficar (mais) controlada na generalidade das regióes portuguesas, os números diários de novos casos atingiam médias observadas só nas primeiras semanas de março, bem como o número de mortes diárias por COVID-19 raramente vinha passando o valor de 5 nas semanas de antecedência. A transcrição da terceira entrevista é a que se segue. 
AGR: Como está o primeiro semestre comparativamente com o primeiro semestre do ano passado?

PRM: Se os meses de janeiro e fevereiro de 2020 até mostravam valores do IETI mais altos do que os respetivos meses de 2019 (em média, 25 pontos percentuais acima), desde março de 2020 que em termos homólogos estamos a ter valores que são inferiores 45 pontos percentuais.

AGR: E o segundo trimestre deste ano comparativamente com período homólogo do ano anterior?

PRM: Claramente negativo. Por exemplo, abril de 2020 valeu 15\% de abril de 2019. Houve uma diminuição do IETI em maio e junho de 2020 menos acentuada mas podemos dizer que houve menos $50 \%$ de dinheiro a circular na região do que há um ano.

AGR: Quais os setores mais afetados?

PRM: Obras públicas e turismo, principalmente. Para lá [dos setores] do índice, a restauração e setores associados (como a distribuição de géneros), a organização de eventos e a hotelaria são claramente afetados.

AGR: Como está a confiança dos transmontanos?

PRM: O Índice mostra a perceção dos fluxos de consumo, investimento e turismo. Tradicionalmente, o consumo mostra a capacidade de resposta a necessidades correntes enquanto o investimento está mais associado à confiança. E aí vemos que a região tem um setor das Obras Públicas que caiu muito em março e abril, mas que desde então não recuperou. Ainda neste último inquérito, o IETI de julho mostrou que $80 \%$ dos respondentes referiu que o volume de obras era similar ao do mês anterior.

AGR: Tendo em conta os dados divulgados pelo INE e os dados que tem do IETI, o que já dá para ver já sobre a economia transmontana com esta pandemia?

PRM: Os dados de hoje apontam quebras que ultrapassam os 15\% para o PIB nacional. Nas grandes crises do passado, como em 1929, a região ficou 'resguardada' de impactes proporcionais devido à sua endogeneidade e menor exposição aos setores globais. Atualmente, a região depende direta e indiretamente do Estado, enquanto não houver 
impactos nos salários reais dos funcionários públicos isso permitirá que a crise na região não seja em magnitude maior. Até lá, e com as previsões em curso, e se fechássemos o ano no primeiro semestre, teríamos uma queda dos rendimentos em redor dos $20 \%$.

\section{REVISÃO CRÍTICA DAS RESPOSTAS DADAS}

Os valores do IETI, quando comparados homologamente, mostram, desde março de 2020, resultados sempre inferiores aos alcançados nos respetivos meses de 2019. Claramente o maior fosso ficou em abril de 2020 (que valeu só 15\% do índice de abril de 2019). No entanto, o valor médio entre março de 2020 e julho de 2020 foi sempre praticamente metade do valor médio entre março de 2019 e julho de 2019. Estes valores, concordando com as projeçôes mais recentes para o conjunto do país, comprovam a prociclicidade (atual) da economia das regióes mais interiores com o conjunto nacional (muito por força da dependência do ciclo dos rendimentos ligados aos fluxos do setor público). Mas comprovam também que a crise foi especialmente simétrica - sentida por todos com intensidade próxima - dentro do território português (quer pela resposta uniforme imposta pelo Estado, quer pela dependência dos rendimentos associados aos estabilizadores automáticos). Ao invés, a crise pandémica que muitos queriam, em termos retóricos, colocar como simétrica no espaço europeu, acabou por revelar-se profundamente assimétrica, quer nas respostas políticas dessincronizadas, quer na gestão da informação sobre as mesmas respostas (especialmente evidente na segunda 'Cimeira Europeia' mais longa, a ocorrida entre os dias 17 e 21 de julho de 2020).

Revendo as respostas dadas a esta terceira entrevista, observo adicionalmente outro aspeto de diferenciação das economias regionais do nosso país. Diversas fontes do período sugerem que o setor nacional das obras públicas não assumia um discurso tão crítico quanto os dados que o Índice da Economia de Trás-os-Montes mostravam para a regiáo. Isto revela aquilo que eu deixava antever na minha resposta - o ciclo do investimento imobiliário e de construção civil está inerte em muitas áreas do país, ficando claramente concentrado nas áreas tradicionalmente suspeitas - áreas litorais e densamente povoadas. 
Finalmente, a gravidade dos impactos na crise em setores específicos da economia nacional ficou ainda confirmada por fontes alternativas. Esses setores mais afetados foram os setores do alojamento, restauração, transportes e armazenagem (de acordo com o jornal 'Dinheiro Vivo', edição de 11 de Maio de 2020, divulgando resultados obtidos a partir de um inquérito encomendado pela Associação Industrial Portuguesa).

\section{EM JEITO DE CONCLUSÃO}

Quando estas linhas foram escritas, a pandemia da COVID-19 ainda existia, quer em Portugal, quer no resto do mundo. A leitura generalista divide-se entre uma ala otimista (onde perfilam aqueles que esperam uma réplica da gripe espanhola que chegou, estragou e desapareceu sem vacina, mas onde também se escutam aqueles que confiam na presença de uma vacina eficaz em tempo próximo) e alas mais pessimistas (que somam transtornos potenciais para vagas futuras, com maior severidade da passada). As leituras dos economistas não se têm distanciado em matizes muito mais distintas, dividindo-se entre correntes libertárias/liberais (protestando contra o confinamento e o aproveitamento do Estado em dilatar a sua influência e peso devido à pandemia, sobrevalorizada em conluio com algumas agendas mediáticas, segundo essas correntes) e correntes neokeynesianas (que pedem um Estado-bombeiro, médico e vigilante à porta de cada um e das instituiçóes), correntes ambientalistas (que exigem mudanças comportamentais para evitar pânicos e pandemias futuras) e correntes apoiantes do decrescimento e da sustentabilidade (exigindo reduçôes da emissão de gases poluentes associados aos ritmos de consumo e de industrialização do presente).

Diversos setores não foram aqui identificados, ainda que o impacto da pandemia também neles esteja a ser significativo. Os setores da própria Comunicação Social, da Cultura e inclusive da Academia (onde cabem as instituiçốes públicas e privadas) são setores profundamente afetados, em Portugal e na generalidade dos outros países. A complexidade dos mesmos, as experiências diversas já recolhidas bem como a incerteza dos cenários em causa aconselharam-me a cingir aos conteúdos das entrevistas transcritas para esta reflexão. Inclusive diversos ensaios têm sido revisitados por autores como Pedro Seixas Miranda (no jornal i), que merecem uma leitura atenta pois provocam-nos a olhar com vistas mais exigentes e longínquas estes problemas. 
Diversas questôes se impóem ainda neste agosto de 2020, desde a incerteza da reação epidémica e concomitantemente socioeconómica, à reabertura das escolas e universidades (com os próprios desafios psicológicos e sociológicos endógenos), até às tensões geradas pela presença/diluição de um Estado mais autoritário, observado na generalidade das sociedades que tiveram experiências de confinamento.

Ao longo da pandemia, com a opção/imposição do teletrabalho, reforcei o trabalho com a rede de coautores nacionais e internacionais (inclusive na assinatura de trabalhos de investigação sobre aspetos mais detalhados da 'Economia da Pandemia'), mas também explorei ferramentas de aulas à distância, recursos alternativos de lecionação e discussão académica, de participação em conferências e seminários em formato 'webinar' bem como de reforço das capacidades de gestão das tensóes pessoais, familiares e profissionais.

No fundo, como respondia a uma outra entrevista, em maio (jornal 'Marcador'/ entrevistado por Carlos Rodrigues): "Se a maioria de nós está a ler estas linhas com saúde, significa que pertence ao grupo maioritário de portugueses que com responsabilidade e com alguma sorte não foi contagiado pela COVID-19 (ou que se o foi, é assintomático...) De qualquer modo, resultado de robustez pessoal, mas também reflexo da responsabilidade de todos os que estabeleceram algum contato de proximidade física nestes dois meses, desde os nossos familiares, vizinhos e até comerciantes com que nos cruzámos. Obviamente, também reflexo das medidas diversas aplicadas ao país. Portanto, esta leitura obriga ao reconhecimento desse sucesso relativo que cada um conseguiu à data." Sucesso, que esperamos, continue para todos à nossa volta. 